\title{
Development of predictive models evaluating the spoilage-delaying effect of a bioprotective culture on different yeast species in yogurt
}

\author{
Line Nielsen, ${ }^{1} \odot$ Maria Rolighed, ${ }^{1,2 *}$ ๑) Ariel Buehler, ${ }^{3} \odot$ Susanne Knøchel, ${ }^{1} \odot$ Martin Wiedmann, ${ }^{3} \odot$ \\ and Cecilie Marvig ${ }^{2}$ \\ ${ }^{1}$ Department of Food Science, University of Copenhagen, Rolighedsvej 26, 1958 Frederiksberg, Denmark \\ ${ }^{2}$ Department of Dairy Bioprotection, Chr. Hansen A/S, Boege Allé 10-12, 2970 Hoersholm, Denmark \\ ${ }^{3}$ Department of Food Science, Cornell University, 341 Stocking Hall, Ithaca, NY 14853
}

\begin{abstract}
Yeast spoilage of fermented dairy products causes challenges for the dairy industry, including economic losses due to wasted product. Food cultures with bioprotective effects are becoming more widely used to help ensure product quality throughout product shelf life. To assist the dairy industry when evaluating product quality throughout shelf life and the effect of bioprotective cultures, we aimed to build stochastic models that provide reliable predictions of yeast spoilage in yogurt with and without bioprotective culture. Growth characterizations of Debaryomyces hansenii, Yarrowia lipolytica, Saccharomyces cerevisiae, and Kluyveromyces marxianus at storage temperatures of 7,12 , and $16^{\circ} \mathrm{C}$ during a 30-d storage period were conducted in yogurt with and without a bioprotective culture containing Lacticaseibacillus rhamnosus strains. The kinetic growth parameters were calculated using the Buchanan growth model, and these parameters were used as baseline values in Monte Carlo models to translate the yeast growth into spoilage levels. The models were developed using 100,000 simulations and they predicted yeast spoilage levels in yogurt by the 4 yeast types. Each modeled yogurt batch was set to be contaminated with yeast at a concentration drawn from a normal distribution with a mean of $1 \log _{10} \mathrm{cfu} / \mathrm{mL}$ and standard deviation of $1 \log _{10} \mathrm{cfu} / \mathrm{mL}$ and stored for $30 \mathrm{~d}$ at a temperature drawn from a normal distribution with a mean of $6.1^{\circ} \mathrm{C}$ and a standard deviation of $2.8^{\circ} \mathrm{C}$. Considering a spoilage level of $5 \log _{10} \mathrm{cfu} /$ $\mathrm{mL}$, the predicted number of spoiled samples was reduced 3-fold during the first $10 \mathrm{~d}$ and by 2 -fold at the end of shelf life when a bioprotective culture was added to the yogurt. The models were evaluated by sensitivity analyses, where the main effect factors were
\end{abstract}

Received December 22, 2020.

Accepted April 27, 2021.

*Corresponding author: dkmrol@chr-hansen.com maximum yeast population, storage temperature, and yeast strain. The models were validated by comparing the model output to actual observed spoilage data from a European dairy using the bioprotective culture. When the model prediction, based on a mixture of the 4 specific yeast strains, was compared with spoilage data from the European dairy, the observed effect of bioprotective cultures was considerably higher than predicted, potentially influenced by the presence of contaminating strains more sensitive to a bioprotective culture than those characterized here. The developed Monte Carlo models can predict yeast spoilage levels in yogurt at specific production settings and how this may be affected by various parameters and addition of bioprotective cultures.

Key words: Monte Carlo simulation, yeast spoilage, yogurt, bioprotective culture

\section{INTRODUCTION}

Fermented dairy products are generally regarded as microbiologically stable because they are most often produced from heat-treated milk, traditionally stored refrigerated, and contain competitive microbiota, which acidify the product by production of organic acids (Garnier et al., 2017b). However, they are susceptible to fungal spoilage, as a large number of fungal species are able to grow under low $\mathrm{pH}$ and low temperature conditions (Fleet, 2011; Garnier et al., 2017b), causing visual defects, physical degradation, and undesirable sensory characteristics of the product (Fleet and Mian, 1987; Ledenbach and Marshall, 2009; Snyder et al., 2016). The most frequent yeast species isolated from fermented dairy products are Torulaspora delbrueckii, Candida spp., Debaryomyces hansenii, Kluyveromyces marxianus, Saccharomyces cerevisiae, Rhodotorula spp., and Yarrowia lipolytica (Suriyarachchi and Fleet, 1981; Fleet and Mian, 1987; Viljoen, 2001; Viljoen et al., 2003; Deák, 2008; Delavenne et al., 2013; Buehler et al., 2017). Fungal contamination of fermented dairy products can derive from the processing environment, 
by airborne transmission of the surfaces (Penney et al., 2004; Mayoral et al., 2005; Temelli et al., 2006; Beletsiotis et al., 2011; Bokulich and Mills, 2013; Radha and Nath, 2014; Buehler et al., 2017), or from the raw materials added postfermentation such as a fruit preparations and other additions (Buehler et al., 2017).

Globally, an estimated 11 to $25 \%$ of dairy products go to waste, depending on the region (FAO, 2011), with a large part wasted due to fungal spoilage. A natural way to decrease fungal spoilage in dairy products is by using food cultures with bioprotective effects that have the ability to delay growth of unwanted microorganisms throughout the product shelf life by competition for nutrients, production of weak organic acids, and potential production of other secondary metabolites (Siedler et al., 2019, 2020).

Fungal spoilage occurs throughout the product shelf life and can originate from very low initial contamination levels. It can be difficult for dairy producers to recognize quality defects of a specific batch before the end of product shelf life. Consequently, it is important to understand and predict how different parameters, such as storage temperature, storage time, and presence of food cultures with bioprotective effects influence product quality. Several studies have developed mathematical models to predict fungal growth in dairy products (Mataragas et al., 2011; Gougouli and Koutsoumanis, 2017; Buehler et al., 2018a), but no studies have previously developed models that predict the effect of bioprotective cultures on growth of several single yeast species in yogurt during shelf life.

The aim of this study was to develop baseline stochastic models to estimate yogurt spoilage from yeasts, taking into consideration the effect of initial contamination level, different yeast species, storage conditions, and use of food cultures with bioprotective effect. Such models can help yogurt producers understand how different parameters influence product quality and use this to support decision making in yogurt quality management.

\section{MATERIALS AND METHODS}

\section{Preparation of Yogurt}

Yogurt was produced by fermentation at $43^{\circ} \mathrm{C}$ of heat-treated $\left(20 \mathrm{~min}\right.$ at $\left.90^{\circ} \mathrm{C}\right)$ semiskim milk $(1.5 \%$ fat; Arla Foods Slagelse dairy center) by a commercial yogurt starter culture (F-DVS YoFlex YF-L901, Chr. Hansen $\mathrm{A} / \mathrm{S}$ ) inoculated at $0.02 \%$ (wt/vol) to final $\mathrm{pH}$ of 4.55 and then stored at $5^{\circ} \mathrm{C}$. Two different yogurt batches were produced; a reference yogurt ( $Y \boldsymbol{r}$ ef) only with yogurt starter culture and a yogurt with biopro- tective culture $(\boldsymbol{Y}+\boldsymbol{b i o p})$ inoculated with both yogurt starter culture and a commercially available culture with bioprotective effect (100U/T, F-DVS FreshQ, Chr. Hansen A/S).

\section{Preparation of Yeast Inoculum and Inoculation of Yogurt Samples}

Yeast growth curves were developed for 4 yeast species previously isolated from spoiled dairy products: (1) $D$. hansenii (Chr. Hansen culture collection, CHCC16374), (2) Y. lipolytica (CHCC16375), (3) S. cerevisiae (CHCC16590), and (4) K. marxianus (CHCC16601). All yeasts were obtained from Chr. Hansen Culture collection (Chr. Hansen A/S) and selected based on their high frequency as spoilage organisms in fermented dairy products (Viljoen et al., 2003; Deák, 2008; Delavenne et al., 2013). Yeasts were kept in a stock solution of Brain Heart Infusion broth (CM225, Oxoid, Thermo Scientic Inc.) and glycerol $\left(20 \%\right.$, Scharlab) at $-80^{\circ} \mathrm{C}$.

Yeast isolates were thawed and diluted in peptone saline diluent (CM0733, Oxoid, Thermo Scientific Inc.) and inoculated into yogurt samples to reach initial concentrations of 10 and $500 \mathrm{cfu} / \mathrm{mL}$. Inoculum levels were confirmed by enumeration on Yeast Glucose Chloramphenicol (YGC) agar (116000YGC, Merck KGaA) after $3 \mathrm{~d}$ of incubation at $20^{\circ} \mathrm{C}$. To assess growth of the different yeasts, $1 \mathrm{~mL}$ was transferred from each inoculated yogurt sample to a microtiter plate $(2 \mathrm{~mL}$, DeepWell PP Plate Natural, Thermo Fisher Scientic Inc.), covered with a breathable lid (Breathe-Easy sealing membrane, Sigma-Aldrich), and incubated at 7, 12, and $16^{\circ} \mathrm{C}$ for $31 \mathrm{~d}$ (Esco isotherm low temperature bod incubator, variation $\left.\pm 0.3^{\circ} \mathrm{C}\right)$.

\section{Development of Growth Curves}

The challenge trial was set up to test all combinations of yeast isolates (D. hansenii, $Y$. lipolytica, $S$. cerevisiae, and K. marxianus), yogurt types (Yref and $Y+$ biop $)$, yeast inoculation levels $(10$ and $500 \mathrm{cfu} / \mathrm{mL})$, and incubation temperatures $\left(7,12\right.$, and $\left.16^{\circ} \mathrm{C}\right)$. These experiments were performed as 3 biological replicates. The initial yeast level was confirmed by diluting $1 \mathrm{~mL}$ of inoculated yogurt 1:1 and plating $250 \mu \mathrm{L}$ on $4 \mathrm{YGC}$ agar plates, giving a detection limit of $10 \mathrm{cfu} / \mathrm{mL}$. Enumeration of yeasts was subsequently performed for each sample every 1 to $3 \mathrm{~d}$ over a period of $31 \mathrm{~d}, 10$ to 15 times in total. Each enumeration was performed from a new well by making appropriate 10-fold dilutions in peptone saline diluent, spotting $20 \mu \mathrm{L}$ on YGC agar in duplicates, and incubating at room temperature for 2 to $3 \mathrm{~d}$. 


\section{Development of Growth Models}

Calculated yeast counts $(\mathrm{cfu} / \mathrm{mL})$ over time were fitted to the Buchanan growth model (Buchanan et al., 1997), the Baranyi and Roberts model (Baranyi and Roberts, 1994), and the Gompertz equation (Gibson et al., 1987), according to the method described by Buehler et al. (2018b). The best model fit was evaluated by comparing the Bayesian Information Criterion calculated for the 3 primary models. Based on the Bayesian Information Criterion, the 3-phase linear model described by (Buchanan et al., 1997) was selected as the primary model. The equations for the kinetic parameters are given in Figure 1.

To characterize the growth as a function of temperature, a minimum notational growth temperature $\left(\mathbf{T}_{\min }\right)$ was calculated using the square-root model described by (Ratkowsky et al., 1982). This calculation was based on the maximum growth rate by strain $\left(\boldsymbol{\mu}_{\max }\right)$ values obtained from the Buchanan growth model for growth at 7,12 , and $16^{\circ} \mathrm{C}$ and initial inoculum of $10 \mathrm{cfu} / \mathrm{mL}$ of $D$. hansenii, Y. lipolytica, S. cerevisiae, and K. marxinanus. Using the approach reported in Pradhan et al. (2009), $\mu_{\max }$ and lag phase by strain $\left(\mathbf{t}_{\mathrm{lag}}\right)$ were transformed to the growth temperatures selected in the model. Growth temperature was modeled as a normal distribution with a mean of $6.1^{\circ} \mathrm{C}$ and a standard deviation of $2.8^{\circ} \mathrm{C}$; this represented the temperature parameters for northern European refrigerators reported by Roccato et al. (2017). Using a normal distribution means that $5 \%$ of the temperatures will be outside the limits set by the standard deviation; for this specific model, $0.15 \%$ of the

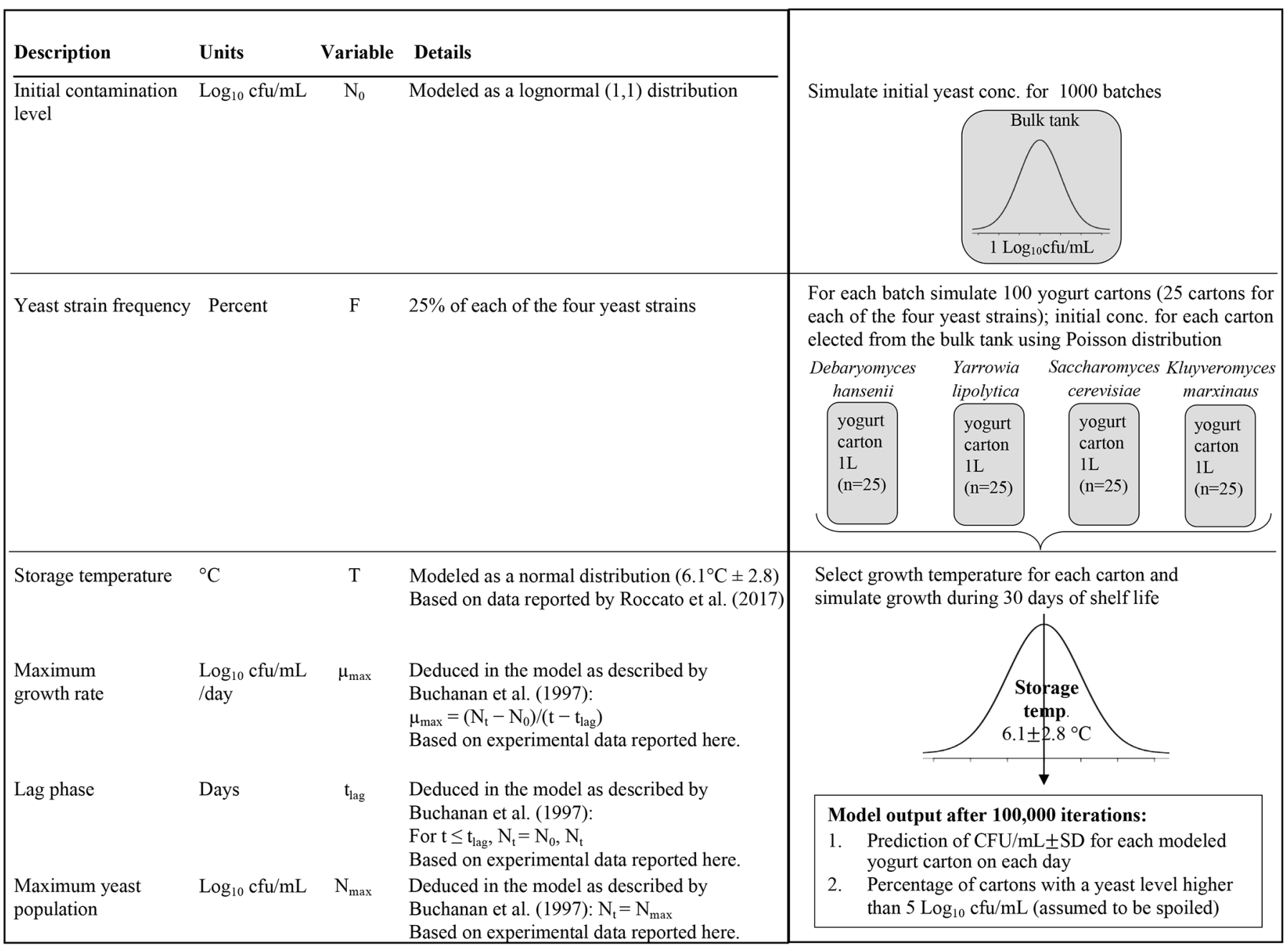

Figure 1. Variables used in Monte Carlo simulations of yeast growth in yogurt produced with and without bioprotective culture together with a schematic overview of the set-up of the Monte Carlo simulations. Conc. = concentration; $\mathrm{N}_{\mathrm{t}}=\log (\mathrm{cfu} / \mathrm{mL}) \mathrm{at}$ time $\mathrm{t} ; \mathrm{N}_{0}=\log$ of initial population. 
simulations used storage temperatures between 16 and $18^{\circ} \mathrm{C}$, with no simulations above $18^{\circ} \mathrm{C}$.

\section{Development of Predictive Models}

Model Parameters. A Monte Carlo simulation model predicting yeast growth in yogurt in 1-L cartons was programmed in $\mathrm{R}$ 3.4.1 (https://www.r-project .org/). Six model parameters were included in the simulation model: (1) initial contamination level by strain $\left(\mathbf{N}_{\mathbf{0}}\right)$, (2) yeast strain frequency $(\mathbf{F}),(3)$ storage temperature $(\mathbf{T})$, (4) $\mu_{\max }$, (5) $\mathrm{t}_{\mathrm{lag}}$, and (6) maximum yeast population by strain $\left(\mathbf{N}_{\max }\right)$, all based on the experimental data collected at $7^{\circ} \mathrm{C}$ at an initial inoculum of $10 \mathrm{cfu} / \mathrm{mL}$ (Figure 1).

Model Simulations. The model was set up to simulate 1,000 batches of yogurt, from each of which $1001-\mathrm{L}$ cartons were taken, giving a total of 100,000 iterations. These 1-L cartons were followed for $30 \mathrm{~d}$ at a storage temperature drawn from a normal distribution with a mean of $6.1^{\circ} \mathrm{C}$ and a standard deviation of $2.8^{\circ} \mathrm{C}$. One simulation model was set up using growth data from the Yref and another model was set up using growth data from the $Y+$ biop. Both models predicted the yeast concentration in the respective yogurt for each day during the shelf-life period. The minimum level of detectable spoilage was set at $5 \log _{10} \mathrm{cfu} / \mathrm{mL}$ (Fleet, 1992), and the percentage of spoiled cartons was predicted for each day (Figure 1A). This limit was based on the lowest level that yeast spoilage becomes evident to the consumer (Fleet, 1992; Garnier et al., 2017a).

Model Assumptions. In the development of the predictive models, it was assumed that all yeast growth derived from the initial yeast contamination of $D$. hansenii, Y. lipolytica, S. cerevisiae, and K. marxianus. Each simulated carton of yogurt was contaminated with 1 yeast strain, a common assumption used in predictive microbiology (Malakar et al., 2003; Buehler et al., 2018a). To give an equal distribution of yeast in the model, the frequency of yogurt cartons contaminated with each yeast strain was set to $25 \%$ (Figure 1A). The initial contamination level in the bulk tank was assumed to be a normal distribution with a mean of $1 \log _{10} \mathrm{cfu} /$ $\mathrm{mL}$ and a standard deviation of $1 \log _{10} \mathrm{cfu} / \mathrm{mL}$. This contamination of each simulated bulk tank was used to model the initial contamination of a given yogurt carton filled from the corresponding bulk tank, using a Poisson distribution. Use of a Poisson distribution is appropriate for the lowest contamination levels modeled here (Guevara et al., 2011; Pouillot and Lubran, 2011; Dagnas and Membré, 2013). Simulated storage temperature was obtained using a normal distribution with a mean of $6.1^{\circ} \mathrm{C}$ and a standard deviation of $2.8^{\circ} \mathrm{C}$; yogurt was assumed to be stored at a constant temperature over the complete shelf-life period (Roccato et al., 2017).

\section{Sensitivity Analysis}

Worst- and best-case sensitivity analyses were used to quantitatively determine the most important factors affecting the predicted number of spoiled cartons (Zwietering and Van Gerwen, 2000). Best-case scenarios were generally defined by changes that reduced the risk of product spoilage, and worst-case scenarios were defined as the changes increasing the risk of spoiled product by the end of shelf life. Effects of the 6 model parameters were evaluated. For $\mathrm{N}_{\max }$, the worst- and best-case scenarios were calculated by an increase and a decrease of $\mathrm{N}_{\max }$ by 20 and $40 \%$, respectively. For the $\mathrm{N}_{0}$, the worstand best-case scenarios were calculated as a $1 \log$ and $2 \log$ decrease and increase of $\mathrm{N}_{0}$, respectively. For the $\mathrm{t}_{\text {lag }}$, the worst- and best-case scenarios were calculated by respectively decreasing and increasing the $t_{\mathrm{lag}}$ by 20 and $40 \%$. For $\mu_{\max }$, the worst- and best-case scenarios were calculated by an increase and a decrease of $\mu_{\max }$ by 20 and $40 \%$, respectively. The worst- and best-case scenarios for the storage temperature were represented by an increase and decrease, respectively, of the mean storage temperature by 3 and $4^{\circ} \mathrm{C}$. For the frequencies of D. hansenii and S. cerevisiae, the worst-case scenario was calculated by decreasing the frequency to 20 and $10 \%$, and the best-case scenario was calculated by increasing the frequency to 30 and $40 \%$. For Y. lipolytica and $K$. marxianus, the worst-case scenario was represented by an increase in the frequency to 30 and $40 \%$, and the best-case scenario was represented by a decrease in the frequency to 20 and $10 \%$. Worst- and best-case scenarios were calculated as the differences between original output at d 30 and the output when 1 model parameter was changed.

\section{Model Validation}

Fungal spoilage data were received from a mediumsized northern European dairy plant that produced yogurt with and without addition of bioprotective culture. Data were collected by sampling 1 sample from every batch of yogurt produced over a period of 16 mo. The products were stored at $8^{\circ} \mathrm{C}$ until the end of shelf life $(35 \mathrm{~d})$. On d 35, the products were opened and examined for visual fungal growth, and data were recorded as growth or no growth by d 35 . The developed predictive models were validated by comparing the predicted 

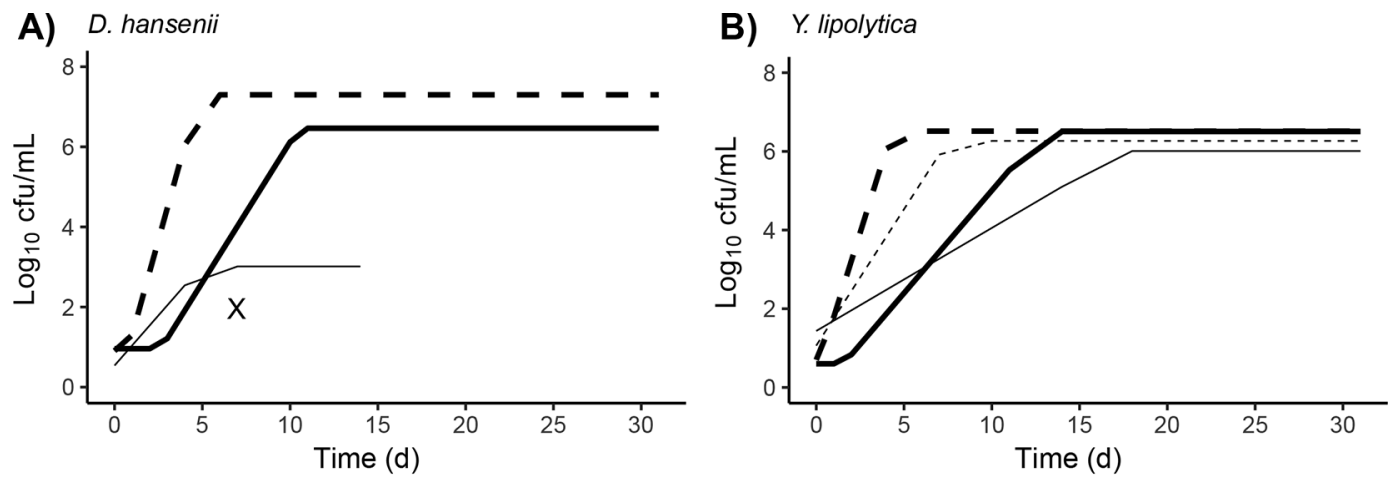

C) S. cerevisiae

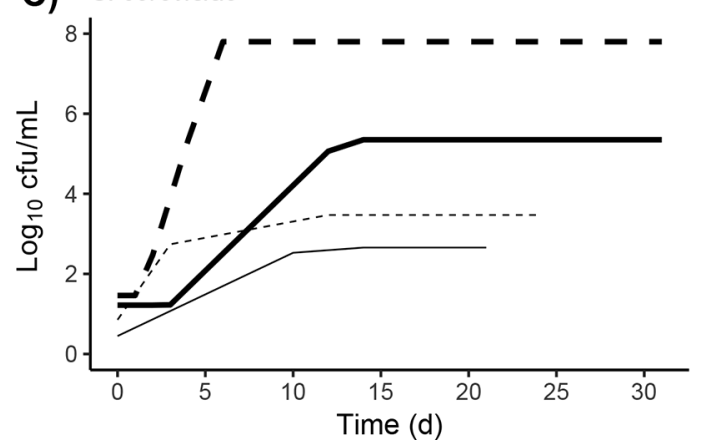

\section{D) K. marxianus}

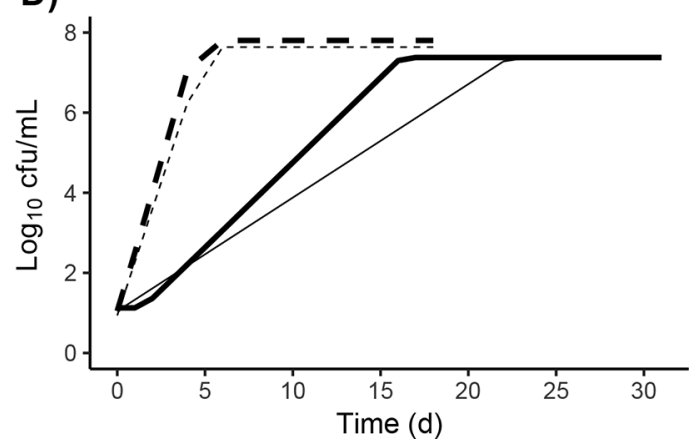

Figure 2. Buchanan-fitted growth curves for Debaryomyces hansenii (A), Yarrowia lipolytica (B), Saccharomyces cerevisiae (C), and Kluyveromyces marxianus (D) inoculated at $10 \mathrm{cfu} / \mathrm{mL}$ into yogurt produced without (bold lines) and with (thin lines) bioprotective culture and stored at $7^{\circ} \mathrm{C}$ (full lines) or $16^{\circ} \mathrm{C}$ (dotted lines). The $\mathrm{X}$ indicates that due to missing raw data, no model could be fitted for $D$. hansenii grown in the presence of bioprotective culture at $16^{\circ} \mathrm{C}$.

effect of the bioprotective culture to the observed effect at the dairy plant. The models were adjusted to predict spoilage at $8^{\circ} \mathrm{C}$.

\section{RESULTS AND DISCUSSION}

This study characterized yeast growth in yogurt and developed predictive models to estimate the spoilage of yogurt over shelf life. These predictive models allowed for prediction of yogurt spoilage caused by different yeast species, as well as the effect of including bioprotective culture in a yogurt product to reduce yeast spoilage.

\section{Fitting of Primary Model}

Three primary models were tested for fitting the growth data: the Buchanan growth model (Buchanan et al., 1997), the Baranyi and Roberts model (Baranyi and Roberts, 1994), and the Gompertz equation (Gibson et al., 1987). The Buchanan model was found to give the best overall fit and gave normally distributed parameters (Figure 2). The Buchanan growth model is also recommended for data sets with few replicates (Buchanan et al., 1997). It is a linear and simpler model compared with the other 2 models, but has been evaluated to describe microbial growth just as accurately as the other models (Buchanan et al., 1997). The fitting performance of the Buchanan growth model to the experimental data was described by the root mean square error (Table 1). A decrease in root mean square error was observed at higher levels of yeast inoculum, when fitting the Yref data (data not shown). However, no systematic deviation of fitting performance was detected between the models for the different yeasts.

The effect of the bioprotective culture varied for the different yeast strains tested (Figure 3), and the resulting growth curves did not follow the growth phases modeled by the primary models for 2 of the yeasts. For $D$. hansenii, the cell counts never exceeded $4 \log _{10} \mathrm{cfu} /$ $\mathrm{mL}$, and cell counts decreased below the detection limit after d 15 (Figure 3A). For S. cerevisiae, the cell count was generally very close to the limit of detection (2.4 $\log _{10} \mathrm{cfu} / \mathrm{mL}$ ), with most counts below the detection limit (Figure 3C), indicating no growth in the presence of bioprotective culture. We consequently concluded that the best way of modeling growth for $S$. cerevisiae and $D$. hansenii was to fit the data with the Buchanan growth model as a stagnation of growth and use the $\mathrm{N}_{\max }$ throughout the shelf life. As a consequence, the 
Table 1. Buchanan-fitted kinetic growth parameters $( \pm \mathrm{SD})^{1}$ of yeast growth in yogurt initially inoculated with $10 \mathrm{cfu} / \mathrm{mL}$ and produced with and without a bioprotective culture stored at $7^{\circ} \mathrm{C}$

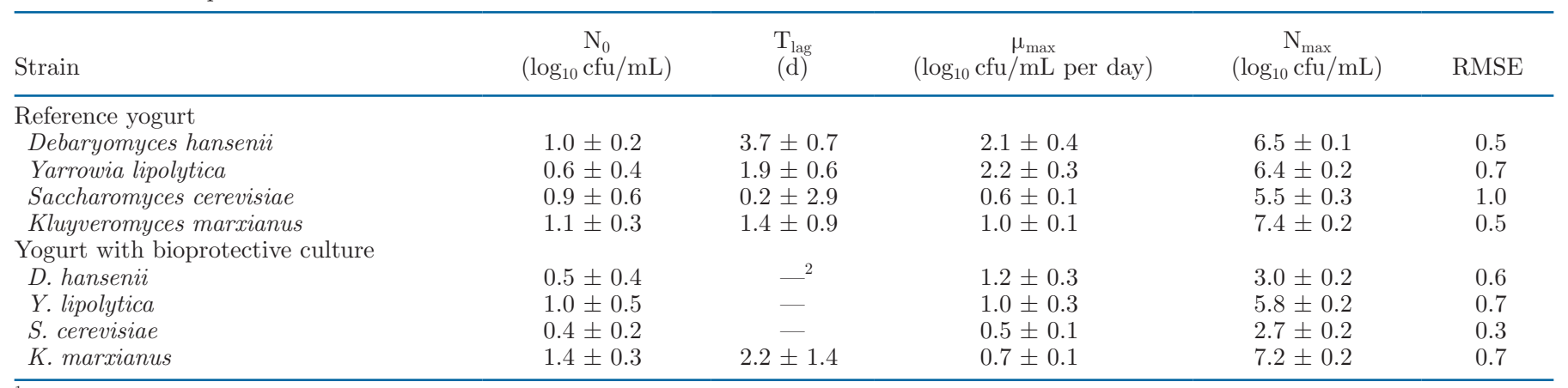

${ }^{1} \mathrm{~N}_{0}=$ initial contamination level by strain; $\mathrm{t}_{\text {lag }}=$ lag phase by strain; $\mu_{\max }=$ maximum growth rate by strain; $\mathrm{N}_{\max }=$ maximum yeast population by strain; RMSE = root mean square error.

${ }^{2}(-)$ Estimation of $t_{\text {lag }}$ was not possible when fitted to the Buchanan growth model for some conditions.

decline in cell count was neglected, providing a more conservative prediction in regard to the effect of the bioprotective culture.

The above challenge encountered when fitting a primary model to inhibition data of yeast in $Y+b i o p$ proved the need for models that are able to accurately fit a stagnation of growth followed by a decline in cell count. Kang et al. (2014) has resolved this challenge by incorporating a nonlinear bacterial inactivation model into the Buchanan growth model for Listeria monocytogenes on cold-smoked salmon. However, to use this approach, the decrease in yeast count is required to be caused by an actual inactivation.

For $Y+b i o p$, insufficient number of data points were obtained in the initial growth phase of D. hansenii, $Y$. lipolytica, and $S$. cerevisiae, and thus $\mathrm{t}_{\mathrm{lag}}$ could not be calculated for these strains (Table 1). As a consequence, the $\mu_{\max }$ might have been underestimated. This is not a limitation of the Buchanan model, but an artifact of the high limit of detection in the challenge trial. In contrast, other studies have observed lag phases up to 10 to 15 d (Viljoen et al., 2003; Mataragas et al., 2011). In accordance with the current study, Salvadó et al. (2011) did not obtain a kinetic parameter for lag phase for 27 different yeast strains growing at 4 to $14^{\circ} \mathrm{C}$, stating that the lag phases were less than $15 \mathrm{~h}$. Interpreting the model from our study, it can be derived that the final $\mathrm{N}_{\max }$ was more important for predicting the effect of the bioprotective culture than the time to reach $\mathrm{N}_{\max }$, considering that $\mathrm{N}_{\max }$ was reached at a lower $\log _{10} \mathrm{cfu} / \mathrm{mL}$ in $Y+$ biop compared with Yref (Figure 2). Fitting the data for $S$. cerevisiae in Yref to the Buchanan growth curve resulted in a difference in $\mathrm{N}_{\max }$ for $7^{\circ} \mathrm{C}$ and $16^{\circ} \mathrm{C}$ at an inoculation level of $10 \mathrm{cfu} / \mathrm{mL}$ (Figure 2C). This might be a result of $S$. cerevisiae not having reached the stationary phase within the trial period $(31 \mathrm{~d})$ at $7^{\circ} \mathrm{C}$. However, this will only affect a prediction if data beyond $31 \mathrm{~d}$ of shelf life is extrapolated.

The final fit of the growth curves showed that $D$. hansenii was the yeast most affected by the bioprotective culture in this study (Figure 2). The S. cerevisiae was highly affected by the variance in temperature, but the presence of the bioprotective culture also had an effect on the final population, illustrated by a lower yeast count. For $Y$. lipolytica and $K$. marxianus, only the growth rate was affected by the bioprotective culture and not the final population.

\section{Monte Carlo Model Structure and Limitations}

To evaluate the benefits of using a bioprotective culture, Monte Carlo models were developed to estimate yeast spoilage levels over time. Although Monte Carlo models and simulations are often used for predictive models, challenges with these approaches include (1) the need for reliable input data sets, which can be difficult to acquire, particularly if models need to be adjusted to specific situations (e.g., different supply chains), and (2) validation is less strict due to the difficulty to generate experimental data of comparable sample size to the number of simulations. By comparison, statistical models (e.g., global mixed effect model) offer more rigorous validation with well-defined performance metrics, but usually require a large amount of data to be expressive (Baker et al., 2018). To be useful in the industry setting, statistical models also need realtime data generation and regular calibration (Baker et al., 2018). Based on these considerations, Monte Carlo models were considered the most appropriate and practical to assess the effect of bioprotective cultures on yogurt shelf life and spoilage. We thus developed Monte Carlo models for yeast spoilage of yogurt, which 

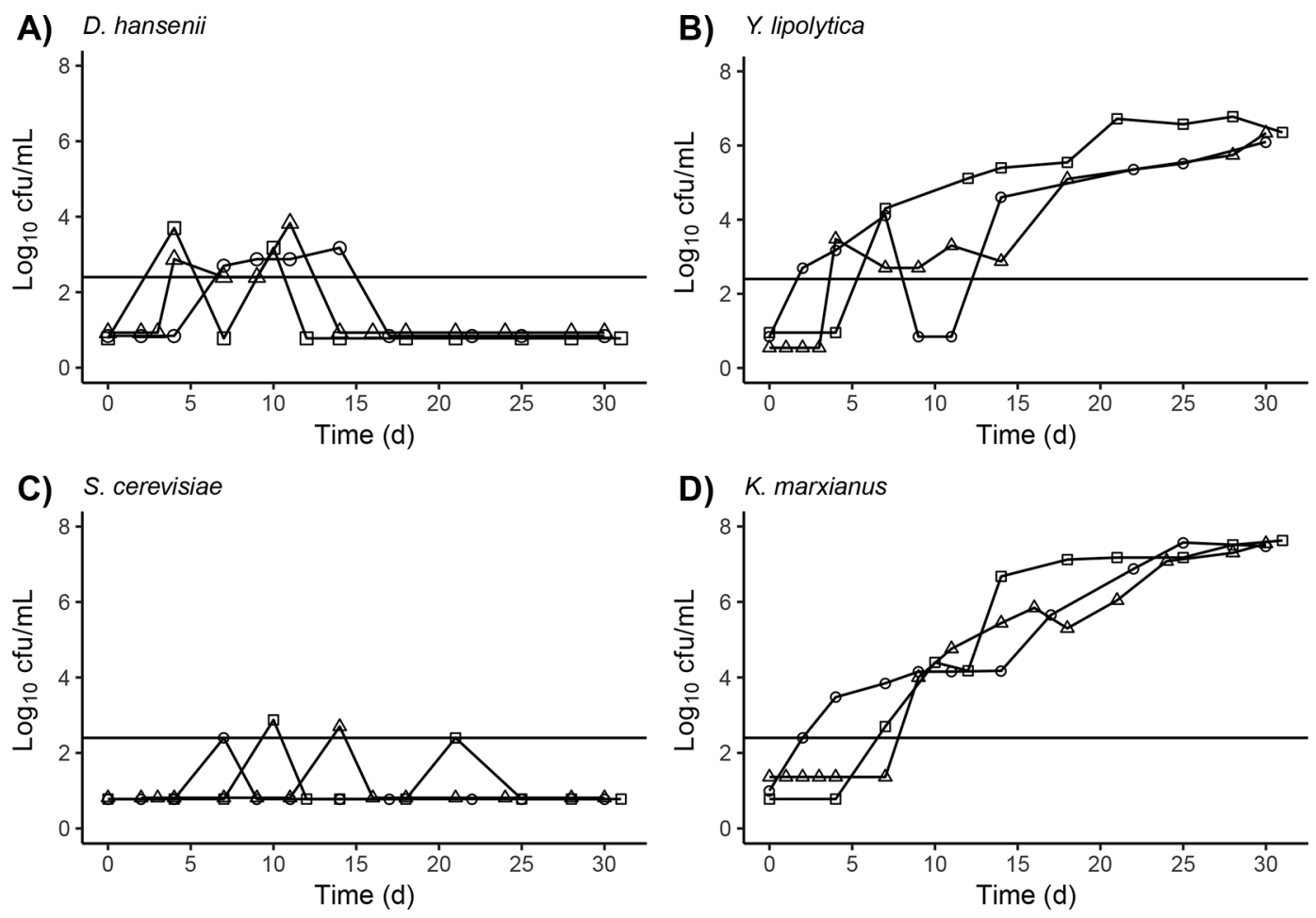

Figure 3. Three biological replicates of growth curves for Debaryomyces hansenii (A), Yarrowia lipolytica (B), Saccharomyces cerevisiae (C), and Kluyveromyces marxianus (D) inoculated at $10 \mathrm{cfu} / \mathrm{mL}$ in yogurt with bioprotective culture stored at $7^{\circ} \mathrm{C}$. Limit of detection is shown as a full horizontal line (with the exception of $\mathrm{d} 0$, where the detection limit was $10 \mathrm{cfu} / \mathrm{mL}$ ); except for $\mathrm{d} 0$, datapoints below the detection limit mean no colonies were present and counts were below the detection limit.

were run with 2 different kinetic growth parameters; 1 for Yref and 1 for $Y+$ biop (Table 1). The models were set to run 1,000 simulations of contaminated yogurt batches, as other studies have reported this to be sufficient (Whiting and Buchanan, 1997; Poschet et al., 2003; Sampedro et al., 2011). It was assumed that 1 carton was only contaminated by 1 yeast strain, as this is a simplified assumption that is common in predictive microbiology (Malakar et al., 2003).

At a dairy plant, the source of contamination, the type of contaminant, as well as level of contaminant can vary throughout the year. Inadequate estimates of realistic contamination levels led to a set-up where all 1,000 yogurt batches were simulated to be contaminated to avoid creating a model that might underestimate the level of contamination and, as a consequence, underestimate the spoilage. All batches were set to have a starting contamination level within a normal distribution with a mean of $1 \log _{10} \mathrm{cfu} / \mathrm{mL}$ and a standard deviation of $1 \log _{10} \mathrm{cfu} / \mathrm{mL}$ (Figure 1). Therefore, the kinetic growth data used in the models were derived from the challenge trial with the low initial level (10 cfu/ $\mathrm{mL}$; Table 1). As a consequence, the models only represented contaminated batches. From each batch, 100 yogurt cartons were sampled, giving a total of 100,000 simulated yogurt cartons (Figure 1). A Poisson distribution was used to model the initial yeast population in the cartons, similar to previous studies (Guevara et al., 2011; Pouillot and Lubran, 2011; Dagnas and Membré, 2013). The lack of data on actual contamination levels, and working with low inoculum levels in general, introduce a source of error to the model development. These considerations were also stated by (Gougouli et al., 2011) when developing a model predicting mold spoilage.

A theoretical $\mathrm{T}_{\min }$ was calculated based on $\mu_{\max }$ at all 3 temperatures for inoculum $10 \mathrm{cfu} / \mathrm{mL}$. The $\mathrm{T}_{\min }$ should be viewed as a conceptual temperature that does not have metabolic significance for psychrophiles and mesophiles (Ratkowsky et al., 1983). The calculated $\mathrm{T}_{\min }$ values were $0.2^{\circ} \mathrm{C}$ for $S$. cerevisiae and $<0^{\circ} \mathrm{C}$ for $D$. hansenii $\left(-20.6^{\circ} \mathrm{C}\right), Y$. lipolytica $\left(-35.1^{\circ} \mathrm{C}\right)$, and $K$. marxianus $\left(-3.7^{\circ} \mathrm{C}\right)$. However, it is likely that growth of a yeast strain would cease when reaching just a few degrees Celsius below $0^{\circ} \mathrm{C}$, as reported by (Deák, 2008). The low $T_{\min }$ values will affect the model predictions because the estimations of $\mu_{\max }$ and $t_{\text {lag }}$ might be overestimated at the set storage temperature $6.1^{\circ} \mathrm{C}$. As a consequence, the model could predict growth at temperatures where growth would not be observed, 
which could result in an overestimation of spoilage. Although we used the original Ratkowsky square-root model (Ratkowsky et al., 1982) to adjust growth rate parameters to different temperatures (in the range of suboptimal growth temperatures), future models may incorporate growth data across a wider range of temperatures with the expanded Ratkowsky square-root model (Ratkowsky et al., 1983) and may also want to explore other approaches to adjust growth parameters to different temperatures, such as the cardinal temperature model with inflection (Rosso et al., 1993).

\section{Sensitivity Analysis}

Sensitivity analyses were performed for both models by varying the model parameters and making a new prediction on d 30 for the percentage of difference in spoiled cartons. The influence of the different input parameters is depicted as best-case and worst-case scenarios, shown as a dark and light gray bar, respectively (Figure 4). The best- and worst-case sensitivity analyses showed that $\mathrm{N}_{\max }$ was the most important parameter for the output for d 30; the worst-case scenarios of $\mathrm{N}_{\max }$ did not influence the output of percentage of spoiled cartons on d 30, as all cartons were already spoiled on this day or would not spoil during the storage period due to the effect of the bioprotective culture. The second-most influential parameter for both models was the storage temperature, which was also a factor expected to greatly influence yeast growth. This emphasized the need for collecting further growth data at different storage temperatures and exploring alternative models to adjust growth temperatures to improve the model to give more reliable predictions. Growth evaluations at lower temperatures would be especially relevant, as refrigeration temperatures can fluctuate down to $3{ }^{\circ} \mathrm{C}$ (Roccato et al., 2017). In this study, lowering the temperature to $7^{\circ} \mathrm{C}$ decreased the growth rate for all yeasts compared with those obtained at $16^{\circ} \mathrm{C}$ (Figure 1). Suriyarachchi and Fleet (1981) and Viljoen et al. (2003) found similar results when investigating the same yeast species at different temperatures.

The effect of the bioprotective culture was more pronounced at $7^{\circ} \mathrm{C}$ for all yeasts compared with $16^{\circ} \mathrm{C}$. However, the factor having the largest effect on the efficacy of the bioprotective culture was the yeast strain (Figure 1). The fact that the yeast strains differed in their susceptibility to the bioprotective culture was reflected in the sensitivity analysis, as the yeast strain had a larger effect on the output of the $Y+$ biop model (Figure 4B) compared with the output of the Yref model (Figure 4A). Knowledge about type or growth characteristics of contaminant being responsible for spoilage in a given product is important for the model output. Therefore, it would be an advantage to include growth data for more fungal species when developing predictive models and to have a better understanding of the potential effect of frequency and level of contaminants. This also illustrated the importance of using data from single strains instead of cocktails when building predictive models because the use of a blend of yeast species would only depict spoilage by the strains less sensitive to bioprotective cultures; a similar conclusion was previously reported by Buehler et al. (2018a). The kinetic growth parameters lag, $\mu_{\max }$, and $\mathrm{N}_{0}$, did not have a large effect on the model outputs, as these parameters did not substantially affect yeast levels at d 30. Sensitivity analysis on d 10 (data not shown) confirmed that these growth parameters had a larger effect than $\mathrm{N}_{\max }$ on the outputs earlier in the shelf life.

\section{Monte Carlo Simulation Outcomes}

The output of the Monte Carlo simulations is shown by frequency distributions of the specific yeast count in all simulated yogurt cartons (Figure 5). This provided a more comprehensive picture of the predictive yeast levels in the product at a specific time, as compared with classical predictive microbiology models. Gougouli and Koutsoumanis (2017), who developed Monte Carlo models for mold spoilage of yogurt, also saw a potential of these kinds of models as a tool for the dairy industry to assess spoilage issues.

The frequency distributions reflect the differences between the yeast strains and their sensitivity to the bioprotective culture that were observed in the modeled growth curves (Figure 1), as several distributions can be observed within each model (Figure 5). To verify what the different distributions represent, separate models were made for the single yeast (data not shown), meaning that all modeled yogurt batches were contaminated by the same yeast strain. We chose not to show the single yeast models because these models give the same information as the model that incorporated all yeasts in the same output (Figure 5). However, the distributions in the single yeast models showed that the large number of cartons with $Y+b i o p$ predicted to have a yeast count around $3 \log _{10} \mathrm{cfu} / \mathrm{mL}$ on d 30 (Figure 5 ) arose from $D$. hansenii and $S$. cerevisiae. The additional peaks in the distribution that were observed at $5.8 \log _{10} \mathrm{cfu} / \mathrm{mL}$ and $7 \log _{10} \mathrm{cfu} / \mathrm{mL}$ (Figure $5, \mathrm{~d} 30$ ) correlated to the single yeast models for $Y$. lipolytica and $K$. marxianus, respectively, in the presence of the bioprotective culture.

This strain-dependent sensitivity to a bioprotective culture is supported by other studies. Delavenne et al. (2013) detected a larger effect of a bioprotective culture against D. hansenii compared with $Y$. lipolytica and $K$. 
marxianus in yogurt. Siedler et al. (2020) also found D. hansenii and S. cerevisiae to be sensitive to bioprotective cultures. Furthermore, a study by Magnusson et al. (2003) observed low sensitivity in an isolate of $K$. marxianus, as they did not find any inhibition of this yeast when investigating 42 isolates of antifungal cultures. Strain differences in sensitivity were additionally observed when using chemical preservatives such as potassium sorbate (Ghadeer et al., 1997). Differences in the sensitivity to bioprotective cultures of the various yeast species evaluated might be explained by differences in mode of action or difference in sensitivity to-

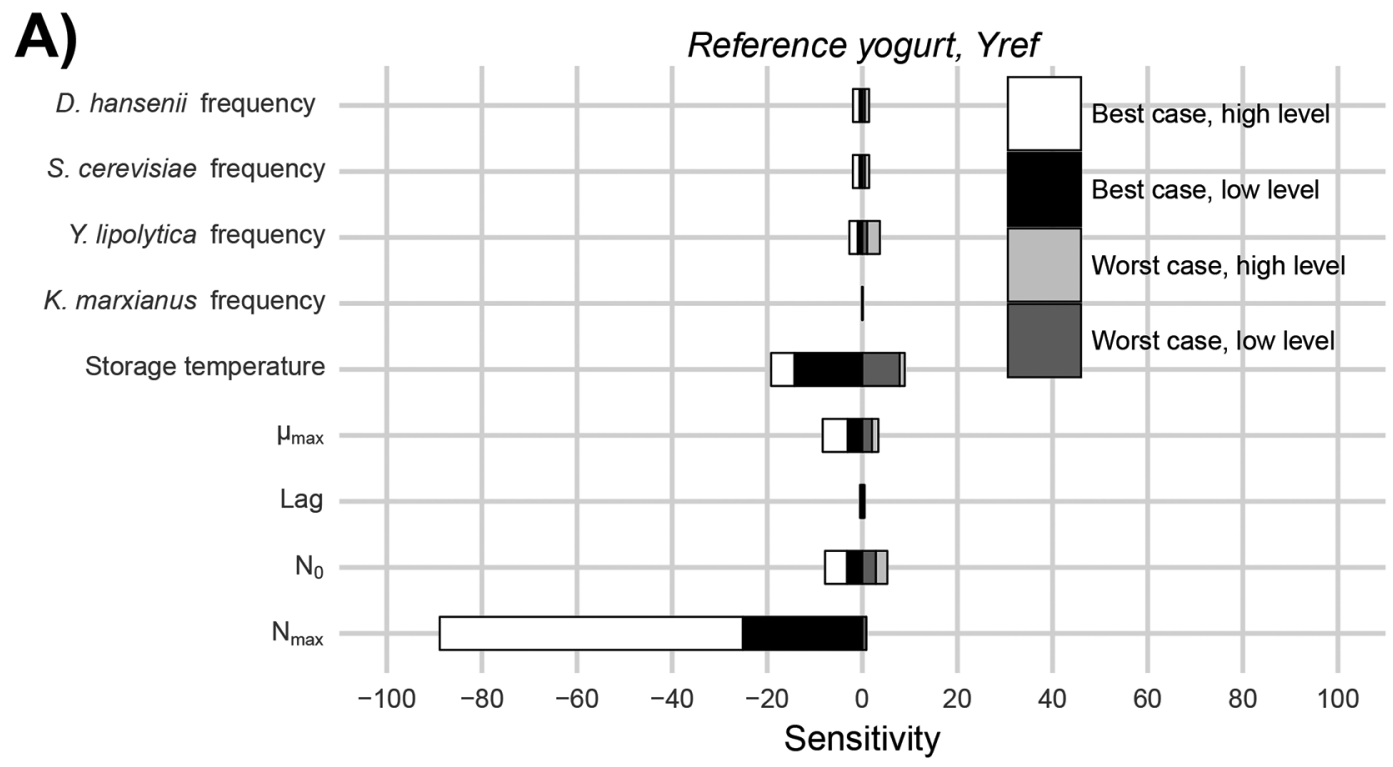

B)

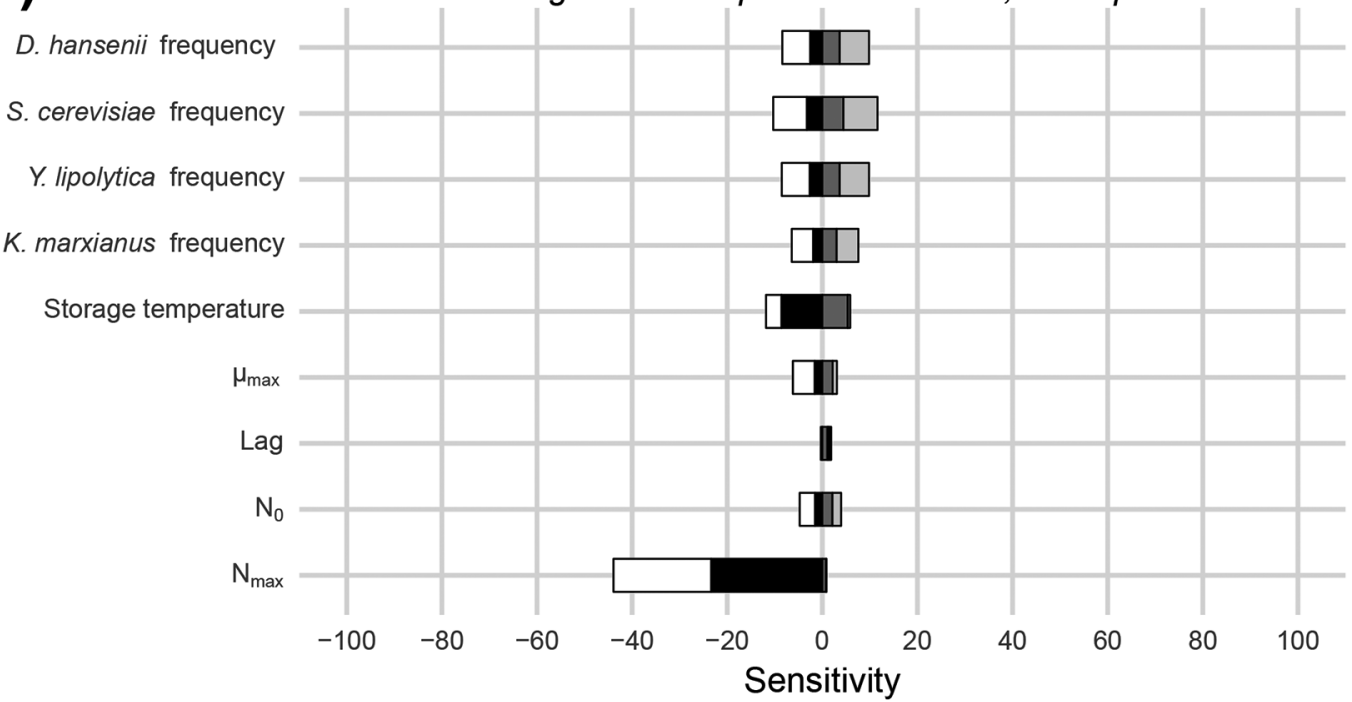

Figure 4. Sensitivity analysis assessing the effects of best-case (high level: white; low level: black) and worst-case (high level: light gray; low level: dark gray) scenarios on the output difference in percentage of spoiled cartons for Monte Carlo simulations for yeast growth of Debaryomyces hansenii, Yarrowia lipolytica, Saccharomyces cerevisiae, and Kluyveromyces marxianus in yogurt produced without (A; Yref) or with addition of bioprotective culture (B; Y+biop) on d 30. All bars are starting at point zero. The parameters were changed as follows. Frequencies of $Y$. lipolytica and K. marxianus: 30\% (worst low), $40 \%$ (worst high), 20\% (best low), and 10\% (best high). Frequencies of D. hansenii and S. cerevisiae: $20 \%$ (worst low), $10 \%$ (worst high), $30 \%$ (best low), and $40 \%$ (best high). Storage temperature: $+3^{\circ} \mathrm{C}$ (worst low) and $+4^{\circ} \mathrm{C}$ (worst high), $-3^{\circ} \mathrm{C}$ (best low), and $-4^{\circ} \mathrm{C}$ (best high). $\mu_{\max }:+20 \%$ (worst low) and $+40 \%$ (worst high), $-20 \%$ (best low), and $-40 \%$ (best high). Lag: $-20 \%$ (worst low), $-40 \%$ (worst high), $+20 \%$ (best low), and $+40 \%$ (best high). $\mathrm{N}_{0}$ : $-1 \log$ (worst low), $-2 \log$ (worst high), +1 log (best low), and +2 log (best high). $\mathrm{N}_{\max }:+20 \%$ (worst low) and $+40 \%$ (worst high), $-20 \%$ (best low) and $-40 \%$ (best high). $\mathrm{N}_{0}=$ initial contamination level by strain; $\mu_{\max }=$ maximum growth rate by strain; $\mathrm{N}_{\max }=$ maximum yeast population by strain. 

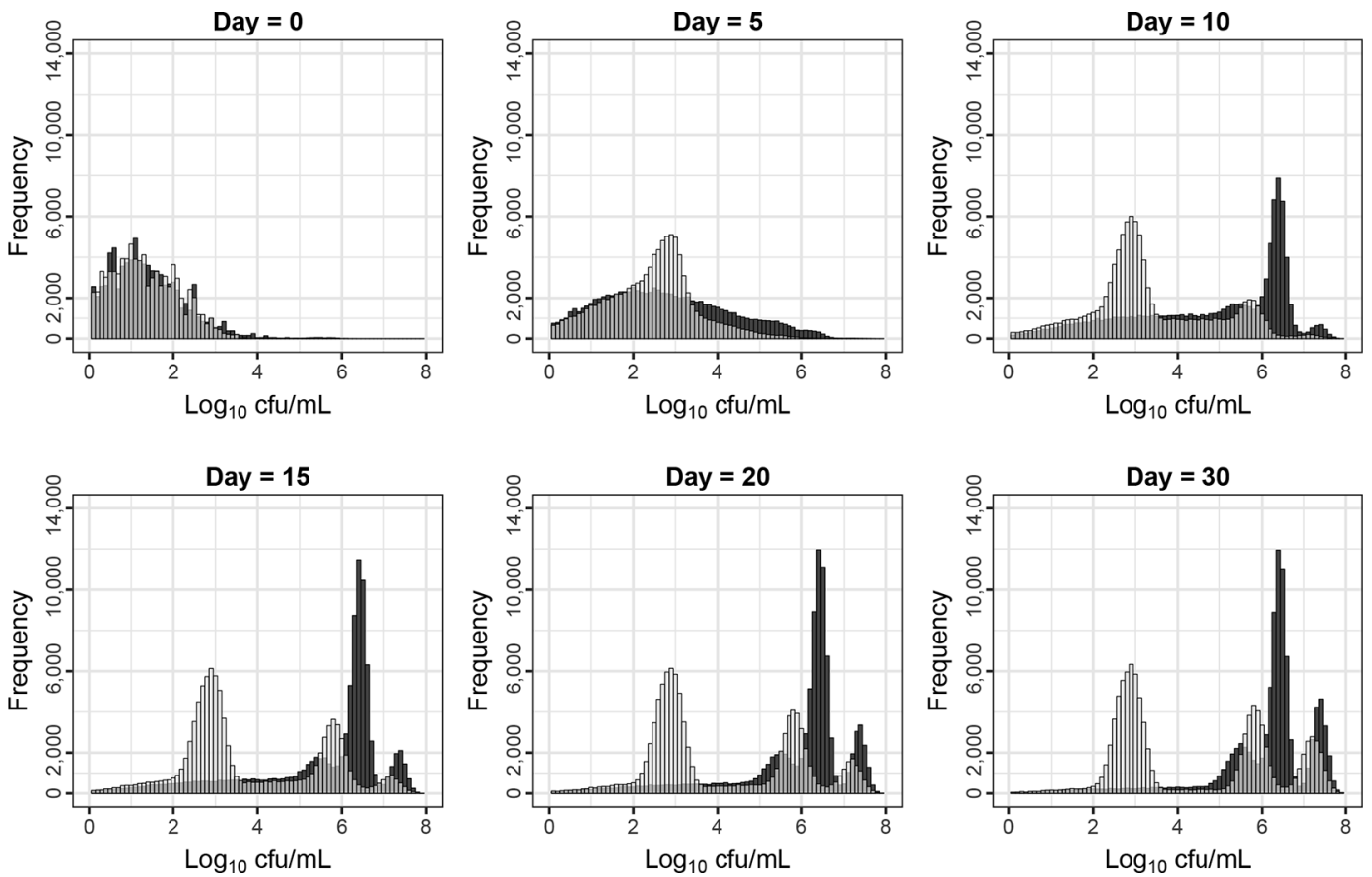

Figure 5. Histograms of the predicted levels of yeast in yogurt produced without (black bars) or with (gray bars) bioprotective culture when stored at $6.1 \pm 2.8^{\circ} \mathrm{C}$ for $0,5,10,15,20$, and $30 \mathrm{~d}$. Monte Carlo simulations comprised 100,000 iterations and were based on 6 model parameters: (1) initial yeast contamination level, (2) yeast strain (Debaryomyces hansenii, Yarrowia lipolytica, Saccharomyces cerevisiae, and Kluyveromyces marxianus) frequency, (3) storage temperature, (4) maximum growth rate, (5) lag phase by yeast strain, and (6) maximum yeast population by yeast strain.

ward one mode of action. Siedler et al. (2020) recently showed that manganese depletion is an essential mode of action by some Lactobacillus for the growth-delaying effect on some yeast species in dairy products. Growth of different yeasts were shown to be affected to different degrees by decrease in manganese levels (Siedler et al., 2020).

To predict the amount of spoiled product on specific days, a limit for visible yeast detection was set at 5 $\log _{10} \mathrm{cfu} / \mathrm{mL}$; this assumed that consumers recognize yogurt with yeast levels above $5 \log _{10} \mathrm{cfu} / \mathrm{mL}$ as spoiled. The exact levels at which spoilage becomes detectable for the 4 specific yeast strains were not investigated. This may have affected the reliability of the output (Mataragas et al., 2011). Considering a spoilage level of $5 \log _{10} \mathrm{cfu} / \mathrm{mL}$, the predicted spoilage level was reduced 3 -fold during the first $10 \mathrm{~d}$ and by 2 -fold at the end of shelf life when bioprotective culture was added to the yogurt (Table 2). This indicates that adding a bioprotective culture during yogurt production is an effective way to reduce spoilage of contaminated products.

The models presented in this study can predict the amount of spoiled product when 4 common spoilage yeast are present in a production. The model can be adjusted to fit specific temperatures and yeast strain frequency. Because the data in the model were recorded for single strains, the percentage assumed spoiled by the single strains can be adjusted to fit a specific contamination scenario (e.g., 10\% of the contamination arising from K. marxianus and $90 \%$ from D. hansenii, or $100 \%$ of 1 yeast strain). If a dairy has a problem with a yeast strain known to have a similar growth-inhibition pattern in the presence of a bioprotective culture as one of the yeast strains tested in this study, the data from this strain can be used and the model can be used to predict an expected spoilage level relevant for the

Table 2. Percentage of cartons estimated to contain $>5 \log _{10} \mathrm{cfu} / \mathrm{mL}$ yeast and expected to be visibly spoiled at different days based on the Monte Carlo predictions for spoilage by Debaryomyces hansenii, Yarrowia lipolytica, Saccharomyces cerevisiae, and Kluyveromyces marxianus (assuming that $25 \%$ of product is contaminated with each of these 4 strains) in yogurt produced with or without addition of bioprotective culture

\begin{tabular}{lcc}
\hline Day & $\begin{array}{c}\text { Spoiled cartons } \\
\text { of reference yogurt }(\%)\end{array}$ & $\begin{array}{c}\text { Spoiled cartons } \\
\text { of yogurt with } \\
\text { bioprotective culture (\%) }\end{array}$ \\
\hline 0 & 0.4 & 0.0 \\
5 & 9.3 & 1.8 \\
10 & 56.3 & 17.0 \\
15 & 74.4 & 30.0 \\
20 & 82.0 & 37.1 \\
30 & 89.0 & 43.6 \\
\hline
\end{tabular}


Table 3. Fungal spoilage data collected at a European medium-size dairy plant over a period of 16 mo for yogurt products stored at $8^{\circ} \mathrm{C}$ at end of shelf life on d 35, along with the result of the Monte Carlo model simulating yeast levels in yogurt also stored at $8^{\circ} \mathrm{C}$

\begin{tabular}{llcc}
\hline Data source & Yogurt type & Total number of samples & $\begin{array}{c}\text { \% of spoiled samples at d 35 } \\
\text { (fold reduction in spoilage) }\end{array}$ \\
\hline European dairy & Normal yogurt & 10,904 & 3.1 \\
& Yogurt with bioprotective culture & 861 & 0.3 (10-fold reduction) \\
Model $^{1}$ & Reference yogurt & 100,000 & 98.4 \\
& Yogurt with bioprotective culture & 100,000 & 49.8 (2-fold reduction) \\
\hline
\end{tabular}

${ }^{1}$ Model estimations assumed that $100 \%$ of yogurt containers were contaminated at $\mathrm{d} 0$.

specific dairy. Therefore, predictive models can be used as a tool that allows the industry to better evaluate the potential of improving control of fungal spoilage by using bioprotective cultures at specific production setting.

\section{Validation of Monte Carlo Models}

In the assessment of the model's ability to predict how the bioprotective culture affects the yeast strains, and thereby the spoilage, actual quality data from an industrial production of yogurt were included. Validation of models has previously been performed based on literature data or a data set not included when building the model (Gougouli et al., 2011; Mataragas et al., 2011; Mertens et al., 2012). These methods might not resemble a real-life situation. In this study, actual data were obtained from a European dairy, which were used to compare the percentage of spoiled products at the end of shelf life from the dairy, to the model-predicted percentage of spoiled products, similar to Buehler et al. (2018a).

The shelf life at the European dairy was 35 d, whereas the developed models only predicted within a shelf life of $30 \mathrm{~d}$. This was considered to be of less importance due to the fact that the predictions made by the model did not change substantially after d 20 (Figure 4). Table 3 shows the spoilage data recorded at $8^{\circ} \mathrm{C}$ by the European dairy, which indicated that $3.1 \%$ of the production without bioprotective cultures were spoiled by the end of shelf life. This spoilage was reduced 10fold by using a bioprotective culture (only $0.3 \%$ spoiled product at d 35). The Monte Carlo models only represented the part of a production that was contaminated, and thus predicts that $98.4 \%$ Yref would be spoiled by the end of shelf life (Table 3). The predictions showed a 2-fold reduction of spoilage caused by addition of bioprotective culture when the yogurt was stored at $8^{\circ} \mathrm{C}$. Hence, the dairy experienced a larger effect of the added bioprotective culture than what was predicted by the model. This might be explained to some extent by the type of contaminant strain, as we have demonstrated that the bioprotective culture inhibited the growth of certain yeast contaminants more than others. The fungal spoilage data collected at the dairy recorded spoilage of both yeast and molds in the same category. This had a large effect on the result of the validation, as molds are generally assumed to be more effectively inhibited by bioprotective cultures, which is supported by results from Buehler et al. (2018a). This could also be caused by higher availability of oxygen at the laboratory scale $(1 \mathrm{~mL})$ compared with industrial scale production, which has a positive effect on yeast growth. Furthermore, the model predictions are based only on contaminated samples, whereas it is not likely that all product packs will be contaminated during production at a dairy.

Our findings indicated that to obtain an exact prediction, detailed knowledge about the contaminants and their frequency is necessary. Therefore, it would be preferred to use a data set for the validation where the relevant contaminants have been identified. However, contaminants can vary in the dairy environment in practice, creating the need for a diverse model that includes several yeast species most often detected as a spoilage organism in yogurt. Here, the validation performed by including actual spoilage data from a dairy supports that our model predictions are conservative, as the models predict more spoilage than observed at the dairy.

\section{CONCLUSIONS}

This study was the first to develop Monte Carlo models to predict the spoilage of yogurt with low initial level of yeast during a shelf-life period of $30 \mathrm{~d}$ at conditions applicable for northern European countries. The sensitivity analysis of the Monte Carlo models showed that the presence of a food culture with bioprotective effect had a larger effect on predicted yeast growth than the initial contamination level and storage temperature. The models can be used by the industry to assess spoilage and the effect of adding a bioprotective culture in a yogurt production with contamination issues. This can be a valuable tool for assisting management decisions regarding reduction of yogurt spoilage, thereby reduc- 
ing economic losses due to food waste. Furthermore, the method for the model development can be used for building new and improved models.

\section{ACKNOWLEDGMENTS}

We acknowledge Tina Hornbæk (Chr. Hansen A/S, Hoersholm, Denmark) for critical reading of the manuscript. The authors Maria Rolighed and Cecilie Marvig are employed by Chr. Hansen A/S, a company that develops and commercializes bacterial cultures. This work was supported by the Department of Dairy Bioprotection of Chr. Hansen A/S, the Department of Food Science of the University of Copenhagen, and the Department of Food Science of Cornell University. The authors have not stated any other conflicts of interest.

\section{REFERENCES}

Baker, R. E., J. M. Peña, J. Jayamohan, and A. Jérusalem. 2018. Mechanistic models versus machine learning, a fight worth fighting for the biological community? Biol. Lett. 14:20170660. https://doi .org/10.1098/rsbl.2017.0660.

Baranyi, J., and T. A. Roberts. 1994. A dynamic approach to predicting bacterial growth in food. Int. J. Food Microbiol. 23:277-294. https://doi.org/10.1016/0168-1605(94)90157-0.

Beletsiotis, E., D. Ghikas, and K. Kalantzi. 2011. Incorporation of microbiological and molecular methods in HACCP monitoring scheme of molds and yeasts in a Greek dairy plant: A case study. Procedia Food Sci. 1:1051-1059. https://doi.org/10.1016/j.profoo 2011.09.157.

Bokulich, N. A., and D. A. Mills. 2013. Facility-specific "house" microbiome drives microbial landscapes of artisan cheesemaking plants. Appl. Environ. Microbiol. 79:5214-5223. https://doi.org/10.1128/ AEM.00934-13.

Buchanan, R. L., R. C. Whiting, and W. C. Damert. 1997. When is simple good enough: A comparison of the Gompertz, Baranyi, and three-phase linear models for fitting bacterial growth curves. Food Microbiol. 14:313-326. https://doi.org/10.1006/fmic.1997.0125.

Buehler, A. J., R. L. Evanowski, N. H. Martin, K. J. Boor, and M. Wiedmann. 2017. Internal transcribed spacer (ITS) sequencing reveals considerable fungal diversity in dairy products. J. Dairy Sci. 100:8814-8825. https://doi.org/10.3168/jds.2017-12635.

Buehler, A. J., N. H. Martin, K. J. Boor, and M. Wiedmann. 2018a. Psychrotolerant spore-former growth characterization for the development of a dairy spoilage predictive model. J. Dairy Sci. 101:6964-6981. https://doi.org/10.3168/jds.2018-14501.

Buehler, A. J., N. H. Martin, K. J. Boor, and M. Wiedmann. 2018b. Evaluation of biopreservatives in Greek yogurt to inhibit yeast and mold spoilage and development of a yogurt spoilage predictive model. J. Dairy Sci. 101:10759-10774. https://doi.org/10.3168/jds .2018-15082.

Dagnas, S., and J. M. Membré. 2013. Predicting and preventing mold spoilage of food products. J. Food Prot. 76:538-551. https://doi .org/10.4315/0362-028X.JFP-12-349.

Deák, T. 2008. Handbook of Food Spoilage Yeasts. CRC Press.

Delavenne, E., R. Ismail, A. Pawtowski, J. Mounier, G. Barbier, and G. Le Blay. 2013. Assessment of lactobacilli strains as yogurt bioprotective cultures. Food Control 30:206-213. https://doi.org/10 .1016/j.foodcont.2012.06.043.

FAO. 2011. Global food losses and food waste - Extent, causes and prevention. Food and Agriculture Organization of the United Nations (FAO)

Fleet, G. 1992. Spoilage yeasts. Crit. Rev. Biotechnol. 12:1-44. https:/ /doi.org/10.3109/07388559209069186.
Fleet, G. H. 2011. Yeast Spoilage of Foods and Beverages. Elsevier B.V.

Fleet, G. H., and M. A. Mian. 1987. The occurrence and growth of yeasts in dairy products. Int. J. Food Microbiol. 4:145-155. https: //doi.org/10.1016/0168-1605(87)90021-3.

Garnier, L., F. Valence, and J. Mounier. 2017a. Diversity and control of spoilage fungi in dairy products: An update. Microorganisms 5:42. https://doi.org/10.3390/microorganisms5030042.

Garnier, L., F. Valence, A. Pawtowski, L. Auhustsinava-Galerne, N. Frotté, R. Baroncelli, F. Deniel, E. Coton, and J. Mounier. 2017b. Diversity of spoilage fungi associated with various French dairy products. Int. J. Food Microbiol. 241:191-197. https://doi.org/10 .1016/j.ijfoodmicro.2016.10.026.

Ghadeer, F., M. I. Mihyar, I. Yamani, and A. K. Al-Sa'ed. 1997. Resistance of yeast flora of labaneh to potassium and sodium benzoate. J. Dairy Sci. 80:2304-2309.

Gibson, A. M., N. Bratchell, and T. A. Roberts. 1987. The effect of sodium chloride and temperature on the rate and extent of growth of Clostridium botulinum type A in pasteurized pork slurry. J. Appl. Bacteriol. 62:479-490. https://doi.org/10.1111/j.1365-2672.1987 .tb02680.x.

Gougouli, M., K. Kalantzi, E. Beletsiotis, and K. P. Koutsoumanis. 2011. Development and application of predictive models for fungal growth as tools to improve quality control in yogurt production. Food Microbiol. 28:1453-1462. https://doi.org/10.1016/j.fm.2011 .07 .006 .

Gougouli, M., and K. P. Koutsoumanis. 2017. Risk assessment of fungal spoilage: A case study of Aspergillus niger on yogurt. Food Microbiol. 65:264-273. https://doi.org/10.1016/j.fm.2017.03.009.

Guevara, L., A. Martínez, P. S. Fernández, and M. Muñoz-Cuevas. 2011. Comparison of probabilistic and deterministic predictions of time to growth of Listeria monocytogenes as affected by $\mathrm{pH}$ and temperature in food. Foodborne Pathog. Dis. 8:141-148. https:// doi.org/10.1089/fpd.2010.0653.

Kang, J., M. J. Stasiewicz, D. Murray, K. J. Boor, M. Wiedmann, and T. M. Bergholz. 2014. Optimization of combinations of bactericidal and bacteriostatic treatments to control Listeria monocytogenes on cold-smoked salmon. Int. J. Food Microbiol. 179:1-9. https:// doi.org/10.1016/j.ijfoodmicro.2014.03.017.

Ledenbach, L.H., and R.T. Marshall. 2009. Microbiological spoilage of dairy products. Pages 41-68 in Compendium of the Microbiological Spoilage of Foods and Beverages. Springer. W. H. Sperber and M. P. Doyle, ed. Springer.

Magnusson, J., K. Ström, S. Roos, J. Sjögren, and J. Schnürer. 2003. Broad and complex antifungal activity among environmental isolates of lactic acid bacteria. FEMS Microbiol. Lett. 219:129-135. https://doi.org/10.1016/S0378-1097(02)01207-7.

Malakar, P. K., G. C. Barker, M. H. Zwietering, and K. Van't Riet. 2003. Relevance of microbial interactions to predictive microbiology. Int. J. Food Microbiol. 84:263-272. https://doi.org/10.1016/ S0168-1605(02)00424-5.

Mataragas, M., V. Dimitriou, P. N. Skandamis, and E. H. Drosinos. 2011. Quantifying the spoilage and shelf-life of yoghurt with fruits. Food Microbiol. 28:611-616. https://doi.org/10.1016/j.fm.2010.11 .009 .

Mayoral, M. B., R. Martín, A. Sanz, P. E. Hernández, I. González, and T. García. 2005. Detection of Kluyveromyces marxianus and other spoilage yeasts in yoghurt using a PCR-culture technique. Int. J. Food Microbiol. 105:27-34. https://doi.org/10.1016/j.ijfoodmicro .2005.06.006.

Mertens, L., E. Van Derlinden, and J. F. Van Impe. 2012. Comparing experimental design schemes in predictive food microbiology: Optimal parameter estimation of secondary models. J. Food Eng. 112:119-133. https://doi.org/10.1016/j.jfoodeng.2012.03.018.

Penney, V., G. Henderson, C. Blum, and P. Johnson-Green. 2004. The potential of phytopreservatives and nisin to control microbial spoilage of minimally processed fruit yogurts. Innov. Food Sci. Emerg. Technol. 5:369-375. https://doi.org/10.1016/j.ifset.2003 .10 .006 .

Poschet, F., A. H. Geeraerd, N. Scheerlinck, B. M. Nicolaï, and J. F. Van Impe. 2003. Monte Carlo analysis as a tool to incorpo- 
rate variation on experimental data in predictive microbiology. Food Microbiol. 20:285-295. https://doi.org/10.1016/S0740 $-0020(02) 00156-9$

Pouillot, R., and M. B. Lubran. 2011. Predictive microbiology models vs. modeling microbial growth within Listeria monocytogenes risk assessment: What parameters matter and why. Food Microbiol. 28:720-726. https://doi.org/10.1016/j.fm.2010.06.002.

Pradhan, A. K., R. Ivanek, Y. T. Gröhn, I. Geornaras, J. N. Sofos, and M. Wiedmann. 2009. Quantitative risk assessment for Listeria monocytogenes in selected categories of deli meats: Impact of lactate and diacetate on listeriosis cases and deaths. J. Food Prot. 72:978-989. https://doi.org/10.4315/0362-028X-72.5.978.

Radha, K., and L. S. Nath. 2014. Studies on the air quality in a dairy processing plant. Indian J. Vet. Anim. Sci. 43:346-353.

Ratkowsky, D. A., R. K. Lowry, T. A. McMeekin, A. N. Stokes, and R. E. Chandler. 1983. Model for bacterial culture growth rate throughout the entire biokinetic temperature range. J. Bacteriol. 154:1222-1226. https://doi.org/10.1128/JB.154.3.1222-1226.1983.

Ratkowsky, D. A., J. Olley, T. A. McMeekin, and A. Ball. 1982. Relationship between temperature and growth rate of bacterial cultures. J. Bacteriol. 149:1-5. https://doi.org/10.1128/JB.149.1.1-5 .1982.

Roccato, A., M. Uyttendaele, and J. M. Membré. 2017. Analysis of domestic refrigerator temperatures and home storage time distributions for shelf-life studies and food safety risk assessment. Food Res. Int. 96:171-181. https://doi.org/10.1016/j.foodres.2017.02 .017 .

Rosso, L., J. R. Lobry, and J. P. Flandrois. 1993. An unexpected correlation between cardinal temperatures. J. Theor. Biol. 162:447-463. https://doi.org/10.1006/jtbi.1993.1099.

Salvadó, Z., F. N. Arroyo-López, J. M. Guillamón, G. Salazar, A. Querol, and E. Barrio. 2011. Temperature adaptation markedly determines evolution within the genus Saccharomyces. Appl. Environ. Microbiol. 77:2292-2302. https://doi.org/10.1128/AEM $.01861-10$.

Sampedro, F., D. Rodrigo, and A. Martínez. 2011. Modelling the effect of $\mathrm{pH}$ and pectin concentration on the PEF inactivation of Salmonella enterica serovar Typhimurium by using the Monte Carlo simulation. Food Control 22:420-425. https://doi.org/10.1016/j foodcont.2010.09.013.

Siedler, S., R. Balti, and A. R. Neves. 2019. Bioprotective mechanisms of lactic acid bacteria against fungal spoilage of food. Curr. Opin.
Biotechnol. 56:138-146. https://doi.org/10.1016/j.copbio.2018.11 .015 .

Siedler, S., M. H. Rau, S. Bidstrup, J. M. Vento, S. D. Aunsbjerg, E. F. Bosma, L. M. McNair, C. L. Beisel, and A. R. Neves. 2020. Competitive exclusion is a major bioprotective mechanism of lactobacilli against fungal spoilage in fermented milk products. Appl. Environ. Microbiol. 86:e02312-19. https://doi.org/10.1128/AEM $.02312-19$.

Snyder, A. B., J. J. Churey, and R. W. Worobo. 2016. Characterization and control of Mucor circinelloides spoilage in yogurt. Int. J. Food Microbiol. 228:14-21. https://doi.org/10.1016/j.ijfoodmicro .2016.04.008.

Suriyarachchi, V. R., and G. H. Fleet. 1981. Occurrence and growth of yeasts in yogurts. Appl. Environ. Microbiol. 42:574-579. https:// doi.org/10.1128/AEM.42.4.574-579.1981.

Temelli, S., Ş. Anar, C. Sen, and P. Akyuva. 2006. Determination of microbiological contamination sources during Turkish white cheese production. Food Control 17:856-861. https://doi.org/10.1016/j foodcont.2005.05.012.

Viljoen, B. C. 2001. The interaction between yeasts and bacteria in dairy environments. Int. J. Food Microbiol. 69:37-44. https://doi .org/10.1016/S0168-1605(01)00570-0.

Viljoen, B. C., A. Lourens-Hattingh, B. Ikalafeng, and G. Peter. 2003. Temperature abuse initiating yeast growth in yoghurt. Food Res. Int. 36:193-197. https://doi.org/10.1016/S0963-9969(02)00138-2.

Whiting, R. C., and R. L. Buchanan. 1997. Development of a quantitative risk assessment model for Salmonella enteritidis in pasteurized liquid eggs. Int. J. Food Microbiol. 36:111-125. https://doi.org/10 .1016/S0168-1605(97)01262-2.

Zwieterin, M. H., and S. J. C. Van Gerwen. 2000. Sensitivity analysis in quantitative microbial risk assessment. Int. J. Food Microbiol. 58:213-221. https://doi.org/10.1016/S0168-1605(00)00275-0.

\section{ORCIDS}

Line Nielsen ๑ https://orcid.org/0000-0002-9602-3965

Maria Rolighed () https://orcid.org/0000-0002-8757-1951

Ariel Buehler @ https://orcid.org/0000-0003-0267-778X

Susanne Knøchel ๑ https://orcid.org/0000-0003-3777-7123

Martin Wiedmann () https://orcid.org/0000-0002-4168-5662 